\title{
Analytical characterization of trace elements (zinc, copper, cadmium, lead and selenium) in saliva of pigs under common pathological conditions in the field: a pilot study
}

Jorge Sánchez ${ }^{1,2}$, Miguel Montilla ${ }^{1}$, Cándido Gutiérrez-Panizo ${ }^{1}$, Juan Sotillo ${ }^{1}$, Pablo Fuentes ${ }^{1,2}$, Ana Montes ${ }^{1}$ (D) and Ana María Gutiérrez ${ }^{1 *}$

\begin{abstract}
Background: This study is focused on the measurement of trace elements (zinc, copper, cadmium, lead and selenium) in the saliva of pigs in order to study their levels on different porcine pathological conditions in the field. The experiment involved 15 pigs without clinical signs of disease and 42 diseased pigs (suffering from lameness, rectal prolapse, fatigue or growth rate retardation). Individual saliva samples were collected, allowing the pigs to chew a sponge each for trace element quantifications through atomic absorption spectrometry (AAS). Since this is the first report on the measurements of trace elements in porcine saliva, a routine analytical validation study was performed for the quantification of all the studied elements. Moreover, the acute phase proteins C-reactive protein (CRP) and haptoblobin (Hp), the total antioxidant capacity (TAC) and adenosine deaminase (ADA) were quantified in the saliva samples for the animal's health status assessment.

Results: Modifications in the levels of acute phase proteins or ADA were only recorded in animals with lameness and rectal prolapse and those with fatigue respectively. Moreover, TAC level changes were observed in pigs with growth-rate retardation. However, alterations in the levels of two or more trace elements were reported for all the different groups of diseased pigs with evident variations within pathologies.

Conclusions: The salivary quantification of trace elements could be considered as a complementary tool to acute phase proteins, TAC and ADA determinations for disease detection and differentiation in the pig and should be explored in greater depth.
\end{abstract}

Keywords: Zn, Cu, Pd, Cd, Se, Salivary levels, Disease detection

\section{Background}

Over the past few years, the use of saliva samples in pigs for diagnosis purposes has been expanded due to its several advantages. The easy, quick, non-invasive and economic sampling allowing unskilled people to collect many samples even in remote places and with minimal

\footnotetext{
* Correspondence: agmontes@um.es

${ }^{1}$ BioVetMed Research Group, Department of Animal Medicine and Surgery, Veterinary School, University of Murcia, Espinardo, 30100 Murcia, Spain Full list of author information is available at the end of the article
}

equipment [1] makes saliva a good option as an alternative diagnostic fluid.

In addition, saliva analysis can reflect systemic conditions in pigs as previously stated [2]. Studies regarding acute phase proteins (APPs) in pigs were based on the C-reactive protein $(\mathrm{CRP})$, haptoglobin $(\mathrm{Hp})$ and serum amyloid A (SAA), indicating that salivary APPs concentration can be used as an early indicator of health status $[3,4]$. Moreover, recent studies performed over the enzyme adenosine deaminase (ADA) in saliva samples showed a powerful and cheap tool for health status

(c) The Author(s). 2020 Open Access This article is distributed under the terms of the Creative Commons Attribution 4.0 International License (http://creativecommons.org/licenses/by/4.0/), which permits unrestricted use, distribution, and reproduction in any medium, provided you give appropriate credit to the original author(s) and the source, provide a link to the Creative Commons license, and indicate if changes were made. The Creative Commons Public Domain Dedication waiver (http://creativecommons.org/publicdomain/zero/1.0/) applies to the data made available in this article, unless otherwise stated. 
assessment in pigs [5]. Other salivary biomarkers such as $\alpha$-amylase [6], cortisol, chromogranin A, immunoglobulin A or testosterone [7] could be used as a practical and non-invasive tool for reflecting the activity of different physiological systems involved in the stress response and the immune system in pigs [8]. Furthermore, a penbased collection of oral fluids has been used to monitor the circulation of several pathogens, such as the porcine reproductive and respiratory virus (PRRS) [9], porcine circovirus Type 2 [10], influenza A virus [11] and Erysipelothrix rhusiopathiae [12].

As such, the importance of measuring trace elements is based on their own roles in the organism (immune system, enzymatic co-factors or cellular structure among others), related to the health status and the interactions between the elements themselves and the changes produced in a diseased organism. Copper $(\mathrm{Cu})$ and zinc $(\mathrm{Zn})$ are essential trace elements for metabolic functions in mammals' cells, both being co-factors for enzymes. $\mathrm{Cu}$ participates in the activation of oxidative enzymes are required for normal cellular metabolism, while $\mathrm{Zn}$ is a cofactor in more than 300 metalloenzymes, which inhibits some bacterial populations in the intestinal tract [13]. Another crucial role of $\mathrm{Zn}$ is that it acts as an integral part of the host immune response by limiting $\mathrm{Zn}$ pathogens' availability [14]. Additionally, salivary $\mathrm{Cu}$ and Zn quantifications, as reported, have a potential power for the diagnosis of human malignant lesions in the oral cavity [15].

Studies on the experimental infection of pigs with Actinobacillus pleuropneumoniae have shown an increase in the levels of $\mathrm{Cu}$ and decrease in the concentrations of $\mathrm{Zn}$ in plasma after 4days of infection [16]. Moreover, other studies have suggested that pathogens can have a competitive advantage over the commensal microbiota under $\mathrm{Zn}$ limiting conditions, thereby being promoted under an inflamed state [17]. Subsequently, the effects of zinc over humoral and cellular immune responses are well recognised in pigs. Zn enhances the immune response to infection and leads to a decreased number and severity of lesions [18].

A role in oxidative stress development has also been reported for some trace elements. Accordingly, $\mathrm{Zn}$ acts as a cofactor for $\mathrm{Cu}-\mathrm{Zn}$ superoxide dismutase enzyme that is a part of the primary antioxidant system of all vertebrates [19]. Furthermore, selenium (Se) participates in several enzymatic reactions in pigs, such as in antioxidant defence mechanism and the inhibition of viral replication [20], while lead $(\mathrm{Pb})$ induces oxidative stress in tissues and cellular components, causing damage to membranes, DNA and proteins [21]. The mechanism underlying lead-induced oxidative damage to membranes is associated with changes in its fatty acid composition [22]. In addition, cadmium (Cd) stimulates the formation of reactive oxygen species, thus causing oxidative damage to erythrocytes and tissues resulting in a loss of membrane functions [23].

The present study aims to perform, for the first time, the quantification of trace elements contained in swine saliva by atomic absorption spectrometry (AAS), and show its potential contribution to the detection and differentiation of health status alterations in pigs in field conditions.

\section{Results \\ Analytical validation}

The all intra-assay coefficient of variation (CV) for the pools with high and low levels of trace elements studied were lower than $9 \%$ (Table 1). Moreover, the inter-assay $\mathrm{CV}$ obtained for all the trace elements were lower than 9.6\% (Table 2).

The dilution of 2 saliva samples with high concentrations of the trace elements resulted in linear regression equations where $\mathrm{x}$ represents the expected trace element level at the dilution and y represents the measured level of the trace element. The correlation coefficients were 0.98 for $\mathrm{Cu}$ and $\mathrm{Zn}, 0.97$ for $\mathrm{Cd}, 0.95$ for $\mathrm{Pb}$ and 0.99 for the Se measurements (Fig. 1).

The limit of detection in the $\mathrm{Cu}$ and $\mathrm{Zn}$ measurements was $0.005 \mu \mathrm{g} / \mathrm{mL}$ and $0.012 \mu \mathrm{g} / \mathrm{mL}$ respectively, while those of $0.015 \mathrm{ng} / \mathrm{mL}, \quad 0.539 \mathrm{ng} / \mathrm{mL}$ and $0.582 \mathrm{ng} / \mathrm{mL}$ were obtained for $\mathrm{Cd}, \mathrm{Pb}$ and Se quantifications respectively. Additional file 1 provides the raw data of the analytical validation study of trace elements in porcine saliva samples.

\section{The measurements of trace elements under clinical conditions}

The median $\mathrm{Cu}$ concentrations were $1.78 \mu \mathrm{g} / \mathrm{mL}$ (25th and 75th percentiles of 1.13 and 2.70 , respectively) in clinically healthy pigs, while the median $\mathrm{Cu}$ levels in all diseased animals, based on statistical significance, were lower and ranged between 0.101 and $0.163 \mu \mathrm{g} / \mathrm{mL}(p<$ $0.05)$. The group of pigs with growth rate retardation included the group of diseased pigs with lower $\mathrm{Cu}$ values (Fig. 2a).

Similar median $\mathrm{Zn}$ concentrations were obtained in pigs with fatigue, and the pigs suffered from rectal prolapse with values of approximately $3 \mu \mathrm{g} / \mathrm{mL}$, which were lower than those observed in clinically healthy pigs $(10.45 \mu \mathrm{g} / \mathrm{mL}, 25$ th and 75 th percentiles of 7,59 and 16, 60 , respectively), but without statistical significance. Moreover, clinically healthy animals showed statistically significant higher $\mathrm{Zn}$ levels than pigs with lameness and those with growth rate retardation $(2.049 \mu \mathrm{g} / \mathrm{mL}, 25$ th and 75th percentiles of 1.36 and 3.04 and $1.029 \mu \mathrm{g} / \mathrm{mL}$, 25th and 75th percentiles of 0.452 and 2.364, respectively) (Fig. 2b). Similarly, statistically significant lower 
Table 1 Assessment of the intra-assay precision of the FAAS assay for the measurement of $\mathrm{Zn}, \mathrm{Cu}, \mathrm{Cd}, \mathrm{Pb}$ and $\mathrm{Se}$ in saliva samples of pigs

\begin{tabular}{|c|c|c|c|c|}
\hline Measurements & & Mean (SD) & CV (\%) & Overall CV (\%) \\
\hline \multirow[t]{2}{*}{ Zn ( $\mu \mathrm{g} / \mathrm{mL})$} & High content & $3.10(0.21)$ & 6.68 & 5.02 \\
\hline & Low content & $0.35(0.01)$ & 3.36 & \\
\hline \multirow[t]{2}{*}{$\mathrm{Cu}(\mu \mathrm{g} / \mathrm{mL})$} & High content & $0.30(0.02)$ & 8.29 & 8.14 \\
\hline & Low content & $0.15(0.012)$ & 7.99 & \\
\hline \multirow[t]{2}{*}{$\mathrm{Cd}(\mathrm{ng} / \mathrm{mL})$} & High content & $1.28(0.041)$ & 3.21 & 5.96 \\
\hline & Low content & $0.33(0.028)$ & 8.71 & \\
\hline \multirow[t]{2}{*}{$\mathrm{Pb}(\mathrm{ng} / \mathrm{mL})$} & High content & 39.55 (1.123) & 2.84 & 5.35 \\
\hline & Low content & $2.45(0.193)$ & 7.85 & \\
\hline \multirow[t]{2}{*}{ Se (ng/mL) } & High content & $7.90(0.634)$ & 8.02 & 6.75 \\
\hline & Low content & 3.15 (0.173) & 5.49 & \\
\hline
\end{tabular}

$\mathrm{Cd}$ concentrations were found in pigs suffering from lameness $(0.6855 \mathrm{ng} / \mathrm{mL})$, rectal prolapse $(0.559 \mathrm{ng} / \mathrm{mL})$ and growth rate retardation $(0.408 \mathrm{ng} / \mathrm{mL})$ in comparison to clinically healthy pigs, with median values of 3.85 $\mathrm{ng} / \mathrm{mL}$ (Fig. 2c). The median Cd concentrations reported for the group of pigs with fatigue were also lower than clinically healthy pigs but without statistical significance.

In the group of pigs without clinical signs of disease, the median $\mathrm{Pb}$ concentrations was $33.45 \mathrm{ng} / \mathrm{mL}$ (25th and 75th percentiles of 24.30 and 58.75 , respectively) with statistically significant low levels of $\mathrm{Pb}$ than those detected in animals suffering from lameness $(8.030 \mathrm{ng} / \mathrm{mL})$, rectal prolapse $(4.68 \mathrm{ng} / \mathrm{mL})$ and fatigue $(7.190 \mathrm{ng} / \mathrm{mL})(p<0.05)$ (Fig. 2d). However, the low Pb levels in pigs with growthrate retardation did not show statistically significant differences compared to the group of clinically healthy pigs.

No statistically significant differences were observed in the Se concentrations between the different groups of study with the exception of pigs with growth-rate retardation that showed statistically significant lower values than those observed in clinically healthy pigs (Fig. 3a). Additional file 2 provides raw individual data of trace elements measurements performed in salivary clinical samples of pigs.

\section{The measurements of acute phase proteins, total} antioxidant capacity and adenosine deaminase activity in the clinical samples

TAC measurements showed similar median values in all the studied groups of animals. Despite the lack of

Table 2 Assessment of the inter-assay precision of the FAAS assay for the measurement of $\mathrm{Cu}, \mathrm{Zn}, \mathrm{Cd}, \mathrm{Pb}$ and $\mathrm{Se}$ in saliva samples of pigs

\begin{tabular}{llllll}
\hline & $\mathrm{Zn}(\mu \mathrm{g} / \mathrm{mL})$ & $\mathrm{Cu}(\mu \mathrm{g} / \mathrm{mL})$ & $\mathrm{Cd}(\mathrm{ng} / \mathrm{mL})$ & $\mathrm{Pb}(\mathrm{ng} / \mathrm{mL})$ & Se $(\mathrm{ng} / \mathrm{mL})$ \\
\hline Mean & 1.07 & 0.97 & 0.93 & 10.30 & 9.12 \\
$\mathrm{SD}$ & 0.067 & 0.013 & 0.089 & 0.743 & 0.431 \\
$\mathrm{CV}(\%)$ & 6.26 & 1.41 & 9.57 & 7.21 & 4.72 \\
\hline
\end{tabular}

statistical significance, lower TAC values were observed in pigs with growth rate retardation (median values of $9.76 \mathrm{mM} / \mathrm{L}$ Trolox equivalent, 25th and 75th percentiles of 7.32 and 16.41, respectively) in comparison to clinically healthy pigs (median values of $20.35 \mathrm{mM} / \mathrm{L}$ Trolox equivalent, 25th and 75th percentiles of 16.26 and 30.95 , respectively) (Fig. 3b).

Additionally, the Hp levels detected in the clinically healthy animals (median value $0.65 \mu \mathrm{g} / \mathrm{mL}$ (25th and 75th percentiles of 0.43 and 0.93 , respectively)) were similar to those of the animals who suffered from fatigue $(0.51 \mu \mathrm{g} / \mathrm{mL})$ and slightly higher than those observed in animals with growth rate retardation $(0.39 \mu \mathrm{g} / \mathrm{mL})$; otherwise, higher median $\mathrm{Hp}$ concentrations were reported in the group of animals with lameness $(2.02 \mu \mathrm{g} /$ $\mathrm{mL}$ ) and rectal prolapse $(2.54 \mu \mathrm{g} / \mathrm{mL})$ (Fig. $4 \mathrm{a})$.

Similar concentrations were recorded for clinically healthy pigs regarding the CRP values (median value $8.86 \mathrm{ng} / \mathrm{mL}$, 25th and 75th percentiles of 7.63 and 15.77, respectively), alongside animals with signs of fatigue (median value $4.82 \mathrm{ng} / \mathrm{mL}$, 25th and 75th percentiles of 0.15 and 6.84, respectively) and pigs with growth rate

Table 3 Correlation coefficients between the trace elements measured and the acute phase proteins and antioxidant status in saliva of pigs. ${ }^{*}$ correlation with statistical significance $(p<$ 0.05)

\begin{tabular}{|c|c|c|c|c|c|c|c|c|}
\hline & CRP & $\mathrm{Zn}$ & $\mathrm{Cu}$ & $\mathrm{Cd}$ & $\mathrm{Se}$ & $\mathrm{Pb}$ & TAC & ADA \\
\hline \multirow[t]{8}{*}{$\mathrm{Hp}$} & $0.59^{*}$ & 0.25 & 0.16 & 0.10 & $0.40^{*}$ & $-0.29^{*}$ & $0.52^{*}$ & $0.53^{*}$ \\
\hline & CRP & -0.11 & -0.01 & -0.03 & 0.05 & 0.01 & 0.25 & $0.29^{*}$ \\
\hline & & $\mathrm{Zn}$ & $0.86^{*}$ & $0.77^{*}$ & $0.73^{*}$ & $0.36^{*}$ & $0.67^{*}$ & -0.22 \\
\hline & & & $\mathrm{Cu}$ & $0.79^{*}$ & $0.60^{*}$ & $0.49^{*}$ & $0.52^{*}$ & $-0.35^{*}$ \\
\hline & & & & $\mathrm{Cd}$ & $0.45^{*}$ & $0.59^{*}$ & $0.38^{*}$ & $-0.37^{*}$ \\
\hline & & & & & $\mathrm{Se}$ & 0.06 & $0.73^{*}$ & 0.09 \\
\hline & & & & & & $\mathrm{Pb}$ & 0.08 & $-0.65^{*}$ \\
\hline & & & & & & & TAC & $0.32^{*}$ \\
\hline
\end{tabular}




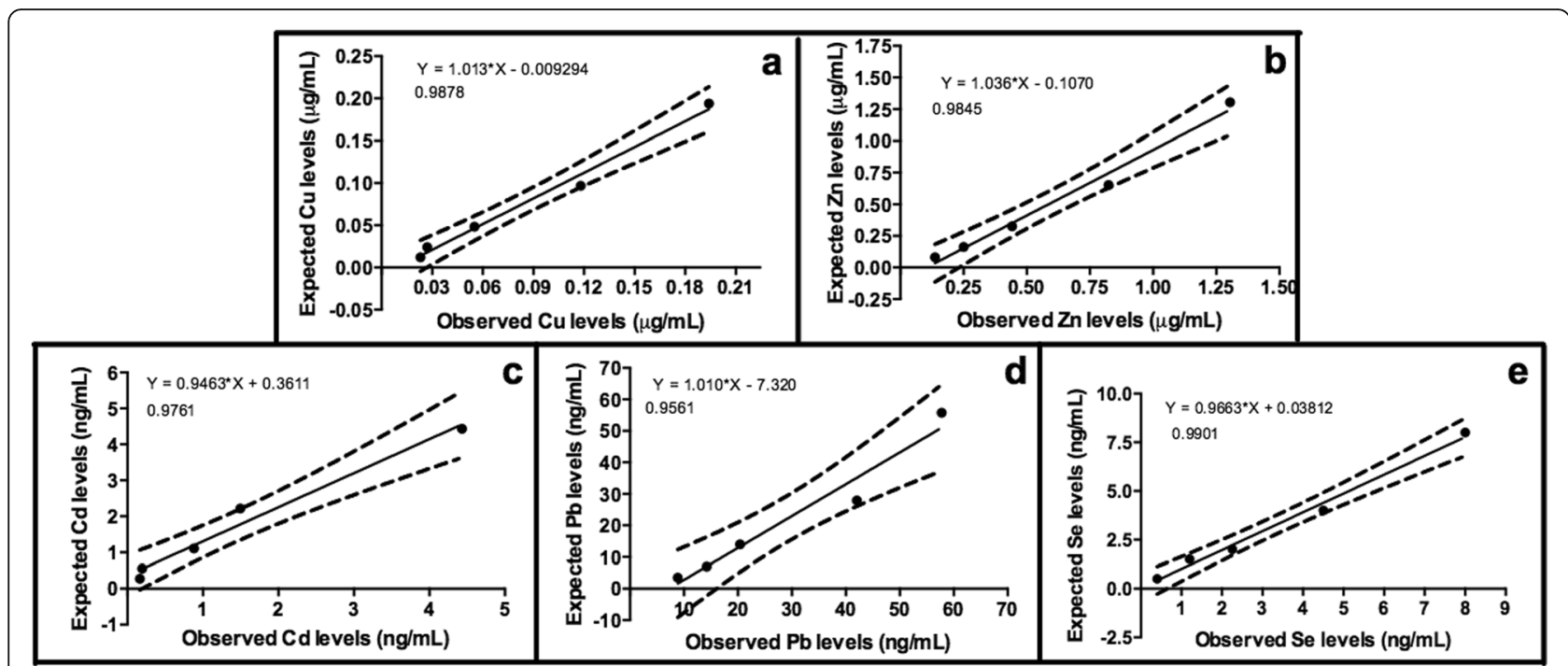

Fig. 1 Linear regression lines indicating the accuracy of the different assay used for measuring $\mathrm{Cu}(\mathbf{a}), \mathrm{Zn}(\mathbf{b}), \mathrm{Cd}(\mathbf{c}), \mathrm{Pd}(\mathbf{d})$ and $\mathrm{Se}(\mathbf{e})$ in serial dilutions of a saliva sample from swine. The slope of the regression lines and the intercepts are indicated in the equation of the curve $(R$ square $=$ correlation coefficients)

retardation (median value $16.80 \mathrm{ng} / \mathrm{mL}$, 25th and 75 th percentiles of 2.19 and 30.36, respectively). In contrast, the concentrations of CRP in pigs suffering from lameness $(48.88 \mathrm{ng} / \mathrm{mL})$ and rectal prolapse $(51 \mathrm{ng} / \mathrm{mL})$ appeared increased compared to clinically healthy pigs (Fig. 4b).
The levels of ADA activity were lower in healthy pigs (median value $65 \mathrm{U} / \mathrm{L}, 25$ th and 75 th percentiles of 60 and 82, respectively) compared to all groups of diseased animals. However, statistically significant differences were observed between healthy pigs and those with lameness, rectal prolapse and fatigue (Fig. 4c). The

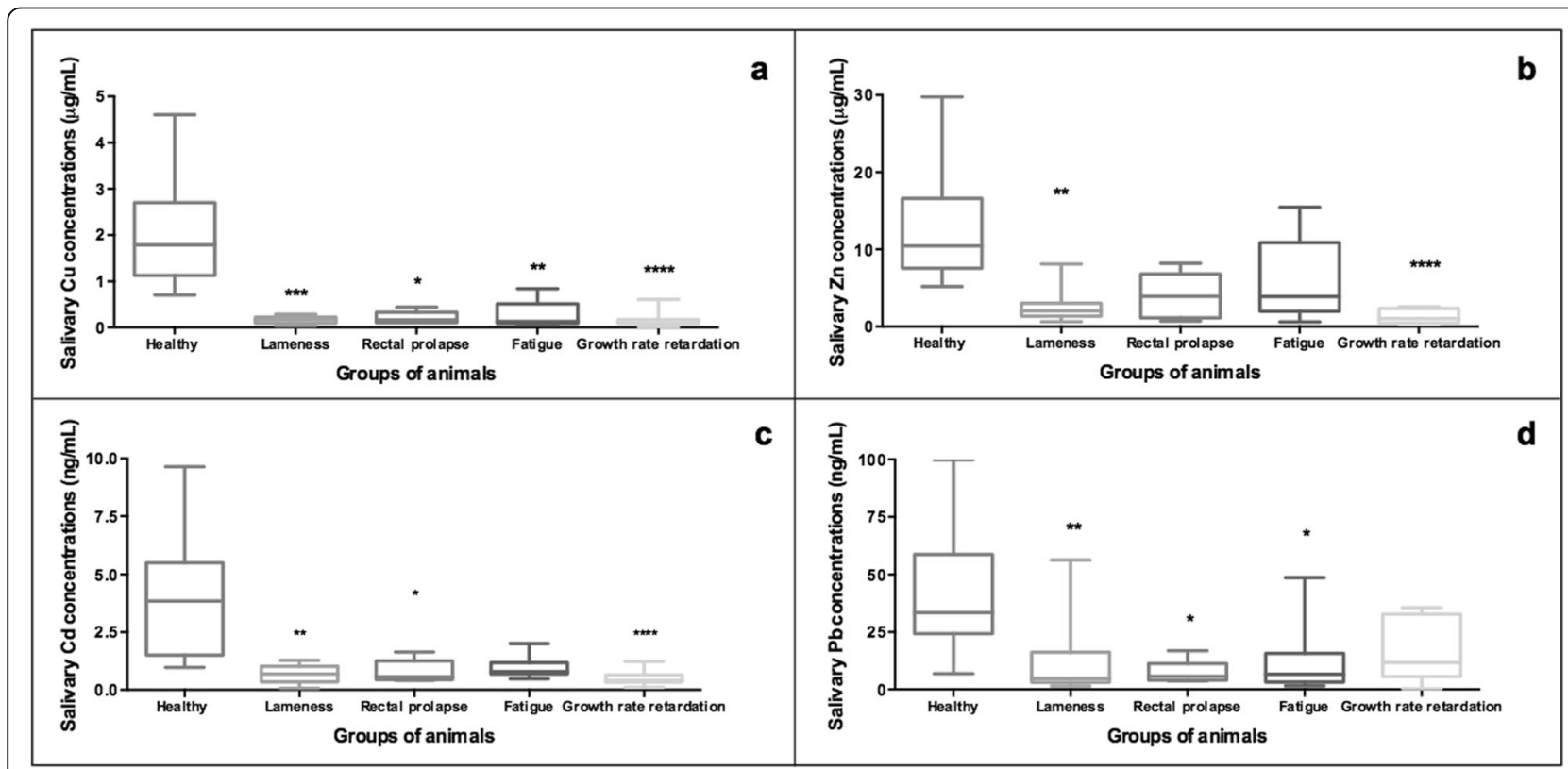

Fig. 2 Concentration of the salivary trace elements, $\mathrm{Cu}(\mathbf{a})$ and $\mathrm{Zn}(\mathbf{b}), \mathrm{Cd}(\mathbf{c})$ and $\mathrm{Pb}(\mathbf{d})$, in clinically healthy pigs $(n=15)$ and in pigs suffered from lameness $(n=13)$, rectal prolapse $(n=9)$, fatigue $(n=9)$ and growth rate retardation $(n=11)$. Box-and-whisker plot showing median (horizontal line inside box), mean (plus symbol), 25 and 75 percentiles (edge of box), 10 and 90 percentiles (whiskers) and individual data points beyond (filled circle); significant pairwise comparisons are noted (adjusted p) 


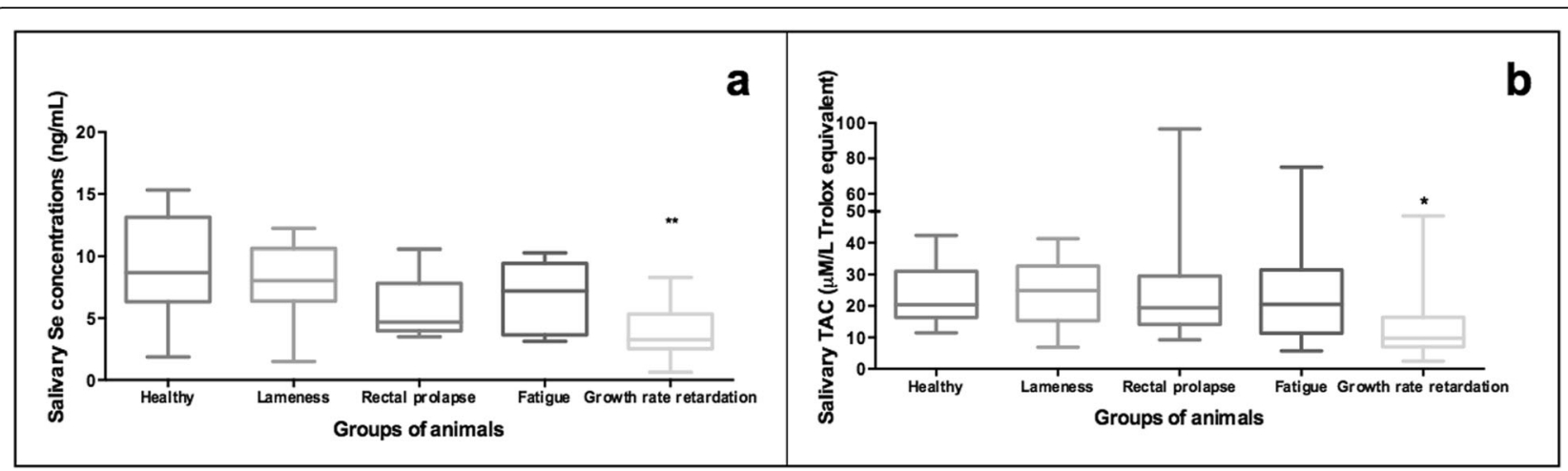

Fig. 3 Concentration of the salivary Se $(\mathbf{a})$ and TAC (b) in clinically healthy pigs $(n=15)$, and in pigs suffered from lameness ( $n=13)$, rectal prolapse $(n=9)$, fatigue $(n=9)$ and growth rate retardation $(n=11)$. Box-and-whisker plot showing median (horizontal line inside box), mean (plus symbol), 25 and 75 percentiles (edge of box), 10 and 90 percentiles (whiskers) and individual data points beyond (filled circle); significant pairwise comparisons are noted (adjusted p)

highest ADA value was observed in animals suffering from rectal prolapse (median value $773.3 \mathrm{U} / \mathrm{L}, 25$ th and 75th percentiles of 380 and 1686, respectively), followed by pigs with lameness (median value $388 \mathrm{U} / \mathrm{L}, 25$ th and 75th percentiles of 267 and 646, respectively) and pigs with fatigue (median value $266 \mathrm{U} / \mathrm{L}, 25$ th and 75 th percentiles of 179 and 499, respectively). Furthermore, the levels of ADA in pigs with growth-rate retardation (median value $156.7 \mathrm{U} / \mathrm{L}, 25$ th and 75th percentiles of 110 and 190, respectively) were slightly higher than those reported in healthy pigs without statistical significance. Additional file 3 provides raw individual data of TAC, $\mathrm{Hp}, \mathrm{CRP}$ and ADA measurements performed in salivary clinical samples of pigs.

Overall, the distribution of the different trace elements and health status markers quantified in healthy pigs and pigs with pathologic conditions (lameness, rectal prolapse, fatigue or growth-rate retardation) could be seen in Fig. 5. Moreover, the general shape observed in each health condition was different when all the 9 markers were considered. Some markers were more pronounced in a specific condition, such as $\mathrm{Cu}$ or $\mathrm{Cd}$ in healthy animals or CRP and $\mathrm{Hp}$ in rectal prolapse or lameness, while other markers were lacking, such us ADA or CRP in healthy animals or $\mathrm{Cu}$ in all pathological conditions.

\section{A first approach to the differences in salivary trace element levels between farms}

The mean concentration of all the studied trace elements was significantly lower in Farm 2, with a documented high sanitary status, compared to the commercial Farm 1 (Fig. 6). However, the levels of the two acute phase proteins studied-Hp (median values of 0.65 vs. $0.55 \mu \mathrm{g} / \mathrm{mL}$ ) and CRP (median values of 8.86 vs. $5.02 \mathrm{ng} / \mathrm{mL}$ ) - and the levels of TAC (median values of 20.35 vs. $17.19 \mathrm{mM} / \mathrm{L}$ Trolox equivalent) and ADA (median values of 65 vs. $91 \mathrm{U} / \mathrm{L}$ ) were similar between the pigs of the two farms. Additional file 4 provides the raw data of measurements performed in saliva samples of healthy pigs from Farm 2.

\section{Correlation analysis}

Statistically significant correlations $(P<0.05)$ were found between the concentrations of the different trace elements analysed and the levels of the health status markers quantified, specifically, $\mathrm{Hp}$ with $\mathrm{Se}$ and $\mathrm{Pb}$, TAC with $\mathrm{Zn}, \mathrm{Cu}, \mathrm{Cd}$ and $\mathrm{Se}$ as well as ADA with $\mathrm{Cu}$, $\mathrm{Cd}$ and $\mathrm{Pb}$ (Table 3). Moreover, statistically significant positive correlations were also found within all the trace elements quantified except for $\mathrm{Se}-\mathrm{Pb}$. No statistical

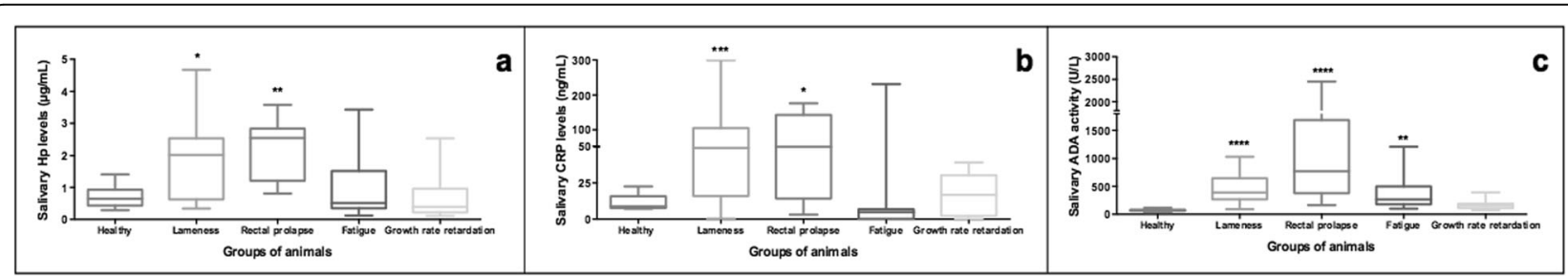

Fig. 4 Concentration of the salivary acute phase proteins, $\mathrm{Hp}(\mathbf{a})$ and $\mathrm{CRP}(\mathbf{b})$ and $\operatorname{ADA}(\mathbf{c})$ in clinically healthy pigs $(n=15)$, and in pigs suffered from lameness $(n=13)$, rectal prolapse $(n=9)$, fatigue $(n=9)$ and growth rate retardation $(n=11)$. Box-and-whisker plot showing median (horizontal line inside box), mean (plus symbol), 25 and 75 percentiles (edge of box), 10 and 90 percentiles (whiskers) and individual data points beyond (filled circle); significant pairwise comparisons are noted (adjusted p) 

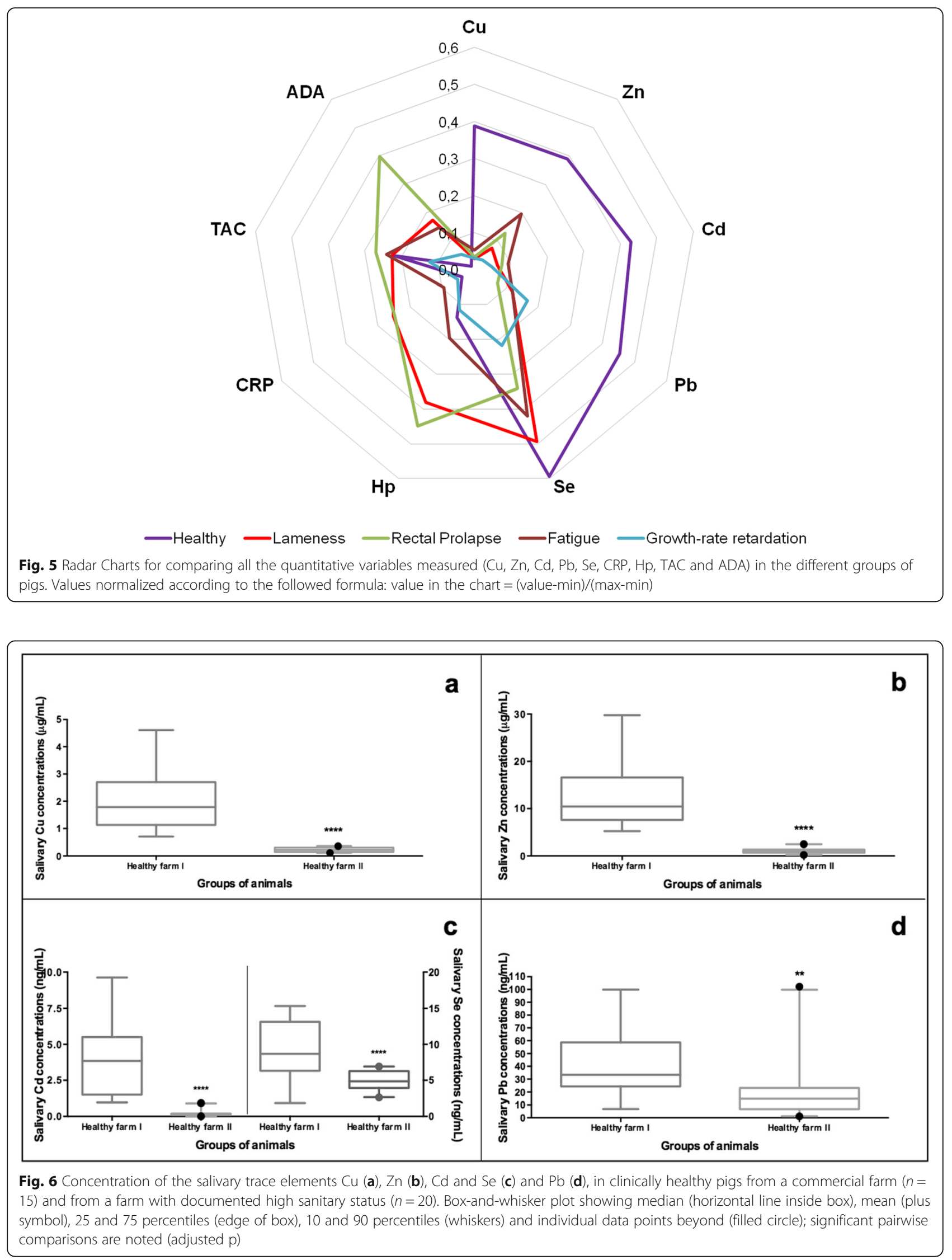
Table 4 Composition of the diet offered to commercial Large White $\times$ Duroc pigs at the fattening and finishing stage of the production system. ${ }^{2}$ Fattening stage: include pigs between 60 and 100 days of age. Finishing stage: include pigs with more than 100 days of age. ${ }^{b}$ From a premix provided per tn of feed: $\mathrm{Cu}$ (from CuSO4.5H2O); Zn (from ZnO2); Se (from Na2SeO3)

\begin{tabular}{|c|c|c|c|c|c|c|c|c|c|c|c|}
\hline \multirow[t]{2}{*}{ Stage $^{a}$} & \multicolumn{8}{|c|}{ Nutrient and analytical composition (\%) } & \multicolumn{3}{|c|}{ Trace elements composition $(\mathrm{g})^{b}$} \\
\hline & Crude protein & Fat & Crude fibre & Ash & Starch & $\mathrm{Ca}$ & $\mathrm{P}$ & $\mathrm{Na}$ & $\mathrm{Cu}$ & $\mathrm{Zn}$ & $\mathrm{Se}$ \\
\hline Fattening & 16.5 & 5.4 & 3.8 & 3.9 & 45.4 & 0.62 & 0.44 & 0.18 & 15 & 100 & 0.34 \\
\hline Finishing & 15.5 & 5.4 & 3.8 & 3.9 & 44.5 & 0.6 & 0.43 & 0.18 & 15 & 100 & 0.30 \\
\hline
\end{tabular}

correlations were observed between the acute phase protein CRP and any other trace elements that were studied.

\section{Discussion}

This is the first-time that the trace elements $\mathrm{Zn}, \mathrm{Cu}, \mathrm{Cd}$, $\mathrm{Pb}$ and $\mathrm{Se}$ were quantified in the saliva samples of pigs, thus resulting in an analytical validation of the methods used for its quantification in saliva samples being performed. Based on the results, atomic absorption spectrometry has been proved to be sensitive enough for the measurements of $\mathrm{Zn}, \mathrm{Cu}, \mathrm{Cd}, \mathrm{Pb}$ and $\mathrm{Se}$ in porcine saliva samples. Moreover, good precisions, acceptable accuracies and limits of detection were observed for all the trace elements studied. This report showed the trace element concentrations in porcine saliva for the first time, to the author's knowledge, thereby warranting additional studies.

Once the validation studies were performed, the possible usefulness of the measurement of trace elements in the saliva samples was analysed for health status assessment in the pigs. Additionally, animals of different health statuses were selected from the same porcine farm to allow for a direct comparison of the trace elements. Furthermore, acute phase proteins, total antioxidant capacity and adenosine deaminase activity were quantified to perform a first health status evaluation of the pigs involved in the study.

The concentrations of $\mathrm{Hp}$ and CRP detected in clinically healthy animals were in agreement with previous studies. The median values observed in the present control animals regarding Hp determinations were the same as those reported for male finishing [24] and fattening pigs [25]. Similarly, CRP median values observed in clinically healthy animals were consistent with previous range values reported for male pigs [26]. From the four groups of diseased animals-pigs suffering from lameness, rectal prolapse, fatigue or growth rate retardation-only those with lameness and rectal prolapse showed alteration in the levels of the acute phase proteins compared to clinically healthy animals. The $\mathrm{Hp}$ levels detected in pigs with lameness and rectal prolapse were higher than the cut-off value $(2.1 \mu \mathrm{g} / \mathrm{mL})$ reported in animals with PRRS in field conditions [25]. Conversely, the CRP levels observed in these groups of diseased animals were higher than those detected in healthy animals in previous studies as well as the current one [27]; however, they were not as high as the CRP cut-off value $(88.52 \mathrm{ng} / \mathrm{mL})$ established for the detection of animals with PRRS [25]. This difference in the magnitude of alteration in the Hp and CRP were in harmony with previous studies performed in serum samples of pigs, in which several sensitivity differences for detecting disease were reported for the different APPs [28], and the incorporation of an APP index was highly suggested [29]. In fact, animals with signs of fatigue and growth rate retardation showed no differences in the median levels of the acute phase proteins in the present study; further studies are necessary to clarify the underlying mechanism of each pathological condition in the field. Thus, only pigs with lameness and rectal prolapse could be classified as suffering from active disease according to our data on acute phase proteins.

TAC levels were quantified in order to obtain further information about the possible oxidative stress implication in each studied disease. Furthermore, the clinically healthy animals showed median salivary TAC values similar to the baseline values recently reported for finishing male pigs [26]. Additionally, the group of pigs suffering from growth-rate retardation showed lower TAC values than those detected in the control pigs, which could indicate that free radicals and the resulting oxidative damage may play an important role in the pathogenesis of the specific process as reported in human medicine [30]; suggestions could include a recommendation for using antioxidant therapy in the treatment of pigs with growth rate retardation, as suggested for lambs [31]. In fact, the involvement of oxidative stress has been evidenced in several porcine pathological conditions such as pneumonia, enteritis or sepsis [32]. However, it has been reported that oxidative stress should be inferred by measuring both oxidants and antioxidants [33]. Therefore, further studies, including a larger number of animals and the quantification of the oxidative damage of each pathological condition, are necessary to corroborate the hypothesis.

Regarding the quantification of the ADA activity, the levels obtained in healthy animals were slightly lower than those previously reported in growing pigs of the same crossbreed origin [5]. Moreover, similar behaviours 
in diseased pigs than those reported in the mentioned study were observed in the present work where animals with growth-rate retardation showed no statistical differences compared to healthy pigs, while other common pathologies such as lameness, rectal prolapse or respiratory conditions produced an increase-of different magnitudes-in the activity levels of ADA.

When trace elements were quantified, alteration in the median levels in at least one element was observed in all the groups of diseased animals studied when compared to the clinically healthy group of pigs. Furthermore, animals with an evident pathological condition (lameness, rectal prolapse or fatigue) showed low levels of $\mathrm{Cu}, \mathrm{Zn}$, $\mathrm{Cd}$ or $\mathrm{Pb}$. Moreover, pigs with growth-rate retardation showed exclusively low Se values. These results agree with the low levels of total serum $\mathrm{Zn}$ levels previously reported in sepsis [14] and Actinobacillus pleuropneumoniae infection [16] with increases after antibiotic treatment [34]. The immunomodulatory function of Zinc makes this metal essential for the immune system [35]; hence, low $\mathrm{Zn}$ levels are connected to a higher susceptibility to infections [36]. The active acute phase response observed in our pigs with evident signs of disease-which concurrently showed low salivary $\mathrm{Zn}$ values-could be translated to poor immune system activation, specifically in animals with lameness, rectal prolapse and fatigue.

During infection, trace elements are crucial factors since the host limits the number of metals such as $\mathrm{Zn}$, as explained above, while filling up the side of infection with other metals such as copper to obtain an antimicrobial effect [37]. The decreased plasma $\mathrm{Zn}$ concentrations have been observed after 4 days of Actinobacillus pleuropneumoniae infection in piglets [16] and $1 \mathrm{~h}$ of sepsis induction in pigs [37]. Similarly, the total serum $\mathrm{Cu}$ levels decreased after sepsis induction with retardation of $3 \mathrm{~h}$ compared to $\mathrm{Zn}$ [37]. We detected low salivary $\mathrm{Zn}$ levels and a significant $\mathrm{Cu}$ reduction in all the diseased pigs. Although our study is limited due to the characteristics intrinsic to field conditions and we could not accurately establish the stage of the disease of our animals-according to the acute phase proteins monitored-it could be postulated that pigs with lameness and rectal prolapse were suffering from a persistent pathological condition with a low immune activation, as previously stated. On the other hand, pigs with fatigue and growth-rate retardation did not suffer from active pathological conditions but presented low activation of the immune system. In any case, further studies are guaranteed to elucidate the levels of salivary trace elements throughout the progression of disease in the pig.

Selenium showed exclusively low salivary levels in pigs suffering from growth-rate retardation in line with the low TAC values. These results are in concordance with the involvement of Se as an integral component of glutathione peroxidase, an antioxidant enzyme [38]. Moreover, selenium is known to participate in the antioxidant defence mechanism for the inhibition of viral replication in pigs [20]. Hence, the Se decrease in parallel to the antioxidant status would be expected.

Furthermore, hazardous pollutants, such as $\mathrm{Cd}$ and $\mathrm{Pb}$, can affect the immune system of farm animals, and preventive measures should be used to avoid their penetration into the stable environment [39]. Moreover, since the baseline salivary values and the salivary toxic levels for these elements have not been established in pigs until now, the mechanisms to explain the higher $\mathrm{Cd}$ and $\mathrm{Pb}$ values observed in clinically heathy animals in our study should be explored in depth.

In addition, differences in the concentration of trace elements between clinically healthy animals from different farms were observed in the present study. However, no variations in the concentrations of APP, TAC or ADA were observed between those animals. It has been recently reported that the concentrations of APP and ADA in porcine saliva samples are influenced by the age, sex and management conditions of pigs [26]. Since those characteristics were similar in the two groups of healthy animals included in our study, no differences were expected in APP, TAC and ADA. Therefore, the variations observed in the concentration of trace elements should not be explained by these factors. Consequently, further studies are necessary to understand which factors could influence the levels of trace elements in saliva samples.

Moreover, it is of relevance that although we did not measure the air pollution in each farm-the first farm is situated in the countryside where the pollution levels would be expected to be lower, and the second farm is situated near the dual carriageway where the higher values would be expected-our results show the opposite effect with higher values in the farm situated in the countryside. Therefore, other sources of pollution, such as water or agricultural residues, should be considered in further studies. In addition, the possible influence of the diet composition on the trace elements levels measured in porcine saliva samples has not been stated before and should be studied in the near future.

The combination of all the biomarkers quantified in the present study, performed by radar chart analysis, showed different pathological patterns for each disease condition. A further number of animals within each condition should be analysed to establish the contribution of each marker in disease differentiation. Subsequently, an optimal algorithm, including the best differential markers, could be prepared for its possible implementation for disease monitoring and/or health status assessment in the field. 


\section{Conclusions}

Our results identified the salivary levels of the trace elements $\mathrm{Zn}, \mathrm{Cu}, \mathrm{Cd}, \mathrm{Pb}$ and Se as promising tools to improve the disease characterisation of pigs in field conditions. However, further large-scale clinical studies are warranted to explain the possible role of the different elements on each pathological condition.

\section{Methods}

\section{Animals and sampling procedures}

Conventional male pigs (Duroc $\mathrm{x}$ Landrace $\mathrm{x}$ Large White) from a farm in the southeast of Spain were selected for this study. The porcine vaccination program of the farm was: a double vaccination against enzootic pneumoniae, at 7 and 28 days of age, a single vaccination against porcine circovirus, at 28 days of age and a double vaccination against Aujezsky disease, at 11 and 14 weeks of age. All the pigs were housed in pens in groups of a maximum of 10 animals with a total unobstructed floor area available in line with the official standards (Directive 2008/120/EC). Moreover, food and water were available ad libitum. The temperature of the barn was automatically controlled.

The farm was three-phase with several outbreaks of porcine reproductive and respiratory syndrome documented in the last 2 months prior to the beginning of the study. A group of growing pigs $(n=42)$ that showed any clinical sign of disease during the routine veterinary clinical examination was selected for the study. From the total 42 diseased pigs sampled, 21 were of around 119 days of age and the other 21 pigs were younger, of around 75 days. The diseased pigs were divided into different groups according to the signs of disease observed during a routine veterinary clinical examination at the farm: one group included those animals with evident clinical signs of lameness $(n=13)$; a second group was composed of pigs suffering from rectal prolapse $(n=9)$; a third group contained pigs with fatigue symptoms $(\mathrm{n}=$ 9); the last group consisted of pigs with retardation in the growth rate without any other signs of disease $(n=$ 11). At the time of sampling, pigs without clinical signs of disease were characterised as animals with possible subclinical infections, thus not being selected as control pigs. Therefore, several months after the documented outbreak, clinically healthy animals from the beginning of the growing stage of the production system of around 70 days of age were randomly selected from the same farm and used as control pigs $(n=15)$. Meanwhile, the other group of clinically healthy animals $(n=20)$ from a different farm-in the same commercial company-were also randomly selected for comparison from a pen of growing pigs of similar ages ( 120 days). This was a closed-cycle farm, with a documented high level of health and sanitary status, and the selected animals were conventional male pigs (Duroc $\mathrm{x}$ Landrace $\mathrm{x}$ Large White) housed in groups of maximum 10 animals but in closed herds of 10 groups with manual temperature control. The vaccination program and other management conditions were the same as the other farm. Composition of the diets offered to all pigs included in the study (pigs at fattening and finishing stages of the production system) were almost the same (Table 4).

For the saliva sample collection, the pigs were allowed to chew individual sponges, attached to a thin flexible metal rod, until the sponges were considerably wet; subsequently, the sponges were placed in specific tubes (Salivette tubes, Sarstedt, Nümbrecht, Germany) and centrifuged at $3000 \mathrm{~g}$ for $10 \mathrm{~min}$, following which, the saliva samples were aliquoted and stored at $-80^{\circ} \mathrm{C}$ until analysis. In each farm, all saliva samples were obtained between $10 \mathrm{a} . \mathrm{m}$. and 11:30 a.m.

All procedures involving animals were approved by the Murcia University Bioethics Committee for Animal Research and followed the recommendations of the European Convention for the Protection of Vertebrate Animals used for Experimental and Other Scientific Purposes (Council of Europe, ETS no. 123). Moreover, the methods used in the experimental phase were aligned with the ARRIVE guidelines and regulations including the oral informed consent of the farm owners prior to their implementation. All animals used in the study continued their routines in the respective growing stages of the production system after the experimental phase. The official veterinary who performed the clinical examination was in charge of the treatment of the diseased animals when necessary.

\section{Measurements of the trace elements}

For trace element quantifications, saliva samples were subjected to acid digestion. Furthermore, for the digestion process, $1 \mathrm{~mL}$ of every saliva sample was applied to a specific digest tube, adding $1 \mathrm{~mL}$ of nitric acid. After incubation at room temperature for $24 \mathrm{~h}$ inside a fume hood, the samples were heated at $120^{\circ} \mathrm{C}$ for an hour; after the addition of $1 \mathrm{~mL}$ of $\mathrm{H}_{2} \mathrm{O}_{2}$, incubation of $1 \mathrm{~h}$ was performed at $120^{\circ} \mathrm{C}$. Finally, the digested samples were cooled at room temperature and filled until $5 \mathrm{~mL}$ with pure water. After the digestion, the samples were stored at $4{ }^{\circ} \mathrm{C}$ until analyses.

The $\mathrm{Zn}$ and $\mathrm{Cu}$ levels were measured by flame AAS using a hollow cathode lamp for $\mathrm{Cu}$ and $\mathrm{Zn}$, with the wavelength $324.7 \mathrm{~nm}$ and $213.8 \mathrm{~nm}$ using an air/acetylene flame. The results were expressed as $\mu \mathrm{g} / \mathrm{mL}$.

The levels of $\mathrm{Cd}, \mathrm{Pb}$ and Se were determined through a graphite furnace AAS using the Zeeman background correction system, graphite tubes with an integrated platform and a hollow cathode lamp for $\mathrm{Cd}$ and ultrAA hollow cathode lamps for $\mathrm{Pb}$ and Se. Moreover, 
palladium nitrate was used as matrix modifier for Se measurements. The results were expressed as $\mathrm{ng} / \mathrm{mL}$.

Certified $\mathrm{Cu}, \mathrm{Zn}, \mathrm{Cd}, \mathrm{Pb}$ and Se standard solutions (Agilent Technologies Spain, Madrid, Spain) were used for constructing the calibration curves of the respective analysis.

\section{Assessment of intra and inter-assay precision}

The intra-assay precision for each trace element was obtained by measuring the concentration of trace element under validation in 2 saliva pools (a pool with high analyte content and the other with low analyte content) 6 times in the same analytical run. Each saliva pool was prepared by mixing an equal amount of saliva from 6 saliva samples with similar trace element concentrations. The inter-assay precision was obtained by measuring a certified standard for each trace element in 5 different days.

Intra- and inter-assay precisions were expressed as the coefficient of variation (CV)-according to the followed formula: $\mathrm{CV}(\%)=(\mathrm{SD} / \mathrm{X}) * 100$-were SD, representing the standard deviation and $\mathrm{X}$ the mean value of the different replicates.

\section{Assessment of assay accuracy}

The assay accuracy was calculated indirectly by linearity under dilution. The protocol involved two saliva samples with high levels of each analyte diluted by $0,6.25,12.5$, 25 and 50\%; their concentrations were measured in duplicate. Furthermore, the accuracy of the assay corresponded to the coefficient of correlation between the expected and the observed measurements.

\section{Assessment of the limit of detection}

The limit of detection was assessed by analysing a zero calibrator (assay buffer) 10 times and calculated as the mean concentration obtained, plus 2 wo standard deviations.

\section{The measurement of acute phase proteins, antioxidant capacity and adenosine deaminase in saliva}

The content of Hp and CRP in saliva samples was quantified using time-resolved fluorometric assays, which were previously developed in house and validated [27, 40].

The total TAC was measured in the saliva samples by the ferric reducing antioxidant power assay, which has been previously validated for the porcine saliva sample [26]. The median coefficients of variation for intra and inter assay were below $11 \%$ with a high accuracy and a limit of detection of $0.80 \mu \mathrm{M} / \mathrm{L}$ Trolox equivalents.

The levels of ADA activity were quantified in the saliva samples using a commercial human assay (BioSystems
S.A., Barcelona, Spain) that has been optimised and validated for use in porcine saliva samples [5].

\section{Statistical analysis}

A normality test, Shapiro-Wilk, was applied to determine whether the results followed a normal distribution pattern. According to the test, the samples had followed a non-normal distribution; therefore, non-parametric Kruskal-Wallis's multiple comparisons test were applied to search for statistically significant differences between the different groups of animals for all the trace elements, acute phase proteins and antioxidant capacity. The possible difference in marker concentrations between clinically healthy animals from the two different farms was studied using the Man-Whitney statistical test. The Spearman correlation was used for the detection of any statistically significant correlation between the studied markers. Moreover, normality and statistical tests were performed using statistical software (GraphPad Prism 6; GraphPad software Inc., Suite, La Jolla, USA).

The intra- and inter-assay CVs and detection limits were calculated using routine descriptive statistical procedures with Microsoft Excel 2000. Further, an ordinary regression analysis was used to investigate linearity under dilution.

\section{Supplementary information}

Supplementary information accompanies this paper at https://doi.org/10 1186/s12917-020-2245-6.

Additional file 1: Raw data of the analytical validation study performed for trace elements measurements in saliva of pigs.

Additional file 2: Raw data of the trace elements measured in saliva samples of pigs under clinical condition.

Additional file 3: Raw data of the Hp, CRP, TAC and ADA concentrations measured in saliva samples of pigs under clinical conditions.

Additional file 4: Raw data of all the measurements performed in saliva samples of healthy pigs from farm 2.
Abbreviations

AAS: Atomic absorption spectrometry; ADA: Adenosine deaminase; APPs: Acute phase proteins; Cd: Cadmium; CRP: C-reactive protein; $\mathrm{Cu}$ : Copper; CV: Coefficient of variation; Hp: Haptoglobin; Pb: Lead; PCV2: Porcine circovirus type 2; PRRS: Porcine reproductive and respiratory virus; SAA: Serum amyloid A; Se: Selenium; TAC: Total antioxidant capacity; Zn: Zinc

\section{Acknowledgements}

Authors are very grateful to professor Ignacio Francisco López García from the Inorganic Chemistry Department of the University of Murcia and Susana Ros Lara form the Department of Animal Medicine and Surgery for its technical help on trace element determinations. Authors also want to thank Francisco Javier Ibañez López from the statistic support section of the University of Murcia for its technical help on statistics.

Authors' contributions

All co-authors of the paper have participated in most phases of the research work, i.e. conception and design (AMG \& AMM), data analysis (JS1, MM, JS2 \& 
PF) and interpretation (JS1, AMG), drafting (AMG\& CGP). Moreover, all authors have read and approved the manuscript submitted for publication.

\section{Funding}

This work was partially supported by the complementary financial support for research groups from the University of Murcia. The funder provided support in the form of funding for reagents and publication fees but did not have any additional role in the design and analysis, decision to publish, or preparation of the manuscript.

\section{Availability of data and materials}

All data generated or analysed during this study are included in this published article and its supplementary information files:

\section{Ethics approval and consent to participate}

This study has been performed in compliance with relevant guidelines (Directive 2010/63/EU). All procedures involving animals were approved by the Murcia University Bioethics Committee for Animal Research and followed the recommendations of the European Convention for the Protection of Vertebrate Animals used for Experimental and Other Scientific Purposes (Council of Europe, ETS no. 123). The verbal consent to participate of the farm owners consist on the explanation of the research purpose and the procedure of saliva sampling. Moreover, the methods used in the experimental phase were in accordance with the ARRIVE guidelines and regulations with the oral informed consent of the farm owners prior to their implementation. All animals used in the study continue its routine in the respective growing stages of the production system after the experimental phase. The official veterinary that perform the clinical examination was the person in charge of the treatment of diseased animals when necessary.

\section{Consent for publication}

Not applicable.

\section{Competing interests}

Authors JS1 and PF were employed by company CefuS.A. The company provided support in the form of salaries for the two authors but did not have any additional role in the study funding, design and analysis, decision to publish, or preparation of the manuscript. Competing interests do not compromise this study. All other authors declare no competing interests.

\section{Author details}

${ }^{1}$ BioVetMed Research Group, Department of Animal Medicine and Surgery, Veterinary School, University of Murcia, Espinardo, 30100 Murcia, Spain. ${ }^{2}$ Cefu S.A., 30840 Alhama de Murcia, Murcia, Spain.

\section{Received: 30 August 2019 Accepted: 16 January 2020} Published online: 30 January 2020

\section{References}

1. Malamud D. Saliva as a diagnostic fluid. Dent Clin N Am. 2011;55:159-78.

2. Gutiérrez AM, Nöbauer K, Soler L, Razzazi-Fazeli E, Gemeiner M, Cerón JJ, Miller I. Detection of potential markers for systemic disease in saliva of pigs by proteomics: a pilot study. Vet Immunol Immunopathol. 2013;151:73-82.

3. Gutiérrez AM, Cerón JJ, Fuentes P, Montes A, Martínez-Subiela S. Longitudinal analysis of acute-phase proteins in saliva in pig farms with different health status. Animal. 2012;6:321-6.

4. Soler L, Gutiérrez A, Cerón JJ. Serum amyloid a measurements in saliva and serum in growing pigs affected by porcine respiratory and reproductive syndrome in field conditions. Res Vet Sci. 2012;93:1266-70.

5. Gutiérrez AM, De La Cruz-Sánchez E, Montes A, Sotillo J, Gutiérrez-Panizo C, Fuentes P, Tornel PL, Cabezas-Herrera J. Easy and non-invasive disease detection in pigs by adenosine deaminase activity determinations in saliva. PLoS One. 2017;12:e0179299.

6. Fuentes M, Tecles F, Gutiérrez A, Otal J, Martínez-Subiela S, Cerón JJ. Validation of an automated method for salivary alpha-amylase measurements in pigs (Sus scrofa domesticus) and its application as a stress biomarker. J Vet Diag Invest. 2011;23:282-7.

7. Escribano D, Campos PH, Gutiérrez AM, Le Floc'h N, Cerón JJ, Merlot E. Effect of repeated administration of lipopolysaccharide on inflammatory and stress markers in saliva of growing pigs. Vet J. 2014;200:393-7.
8. Escribano D, Gutiérrez AM, Tecles F, Cerón JJ. Changes in saliva biomarkers of stress and immunity in domestic pigs exposed to a psychosocial stressor. Res Vet Sci. 2015;102:38-44.

9. Kittawornrat A, Prickett J, Chittick W, Wang C, Engle M, Johnson J, Patnayak D, Schwartz T, Whitney D, Olsen C, Schwartz K, Zimmerman J. Porcine reproductive and respiratory syndrome virus (PRRSV) in serum and oral fluid samples from individual boars: will oral fluid replace serum for PRRSV surveillance? Virus Res. 2010;154:170-6.

10. Prickett JR, Johnson J, Murtaugh MP, Puvanendiran S, Wang C, Zimmerman $J$ J, Opriessnigm T. Prolonged detection of PCV2 and anti-PCV2 antibody in oral fluids following experimental inoculation. Transbound Emerg Dis. 2011; 58:121-7.

11. Detmer SE, Patnayak DP, Jiang Y, Gramer MR, Goyal SM. Detection of Influenza A virus in porcine oral fluid samples. J Vet Diag Invest. 2011;23:241-7.

12. Giménez-Lirola LG, Xiao $C T$, Zavala M, Halbur PG, Opriessnig T. Improving ante mortem diagnosis of Erysipelothrix rhusiopathiae infection by use of oral fluids for bacterial, nucleic acid, and antibody detection. J Microbiol Meth. 2013;92:113-21.

13. Medardus JJ, Molla BZ, Nicol M, Morrow WM, Rajala-Schultz PJ, Kazwala R, Gebreyes WA. In-feed use of heavy metal micronutrients in U.S. swine production systems and its role in persistence of multidrug-resistant salmonellae. Appl Environ Microbiol. 2014;80:2317-25.

14. Hoeger J, Simon TP, Doemming S, Thiele C, Marx G, Schuerholz T, Haase H. Alterations in zinc binding capacity, free zinc levels and total serum zinc in a porcine model of sepsis. Biometals. 2015;28:693-700.

15. Ayinampudi BK, Narsimhan M. Salivary copper and zinc levels in oral premalignant and malignant lesions. J Oral Maxillofac Pathol. 2012;16:178-82.

16. Humann-Ziehank E, Menzel A, Roehrig P, Schwert B, Ganter M, HennigPauka I. Acute and subacute response of iron, zinc, copper and selenium in pigs experimentally infected with Actinobacillus pleuropneumoniae. Metallomics. 2014;6:1869-79.

17. Gielda LM, DiRita VJ. Zinc competition among the intestinal microbiota. MBio. 2012;3(4):e00171-12.

18. Leite FL, Vasquez E, Vannucci FA, Gebhart CJ, Rendahl A, Torrison J, Mueller A, Winkelman NL, Ramb ZJ, Isaacson RE. The effects of zinc amino acid complex supplementation on the porcine host response to Lawsonia intracellularis infection. Vet Res. 2018;49:88.

19. Swain N, Ray JG. Altered trace element level and antioxidant activity in whole blood of oral leukoplakia and cancer patients in comparison with healthy controls. Int J Oral Maxillofac Implants. 2011;2:2-6.

20. Chen X, Ren F, Hesketh J, Shi X, Li J, Gan F, Huang K. Selenium blocks porcine circovirus type 2 replication promotion induced by oxidative stress by improving GPx1 expression. Free Radic Biol Med. 2012;53:395-405.

21. Patra RC, Rautray AK, Swarup D. Oxidative Stress in Lead and Cadmium Toxicity and Its Amelioration. Vet Med Int. 2011;2011:457327.

22. Knowles SO, Donaldson WE. Dietary modification of lead toxicity: effects on fatty acid and eicosanoid metabolism in chicks. Comp Biochem Physiol C Toxicol Pharmacol. 1990;95:99-104.

23. Sarkar S, Yadav P, Bhatnagar D. Lipid peroxidative damage on cadmium exposure and alterations in antioxidant system in rat erythrocytes: a study with relation to time. Biometals. 1998;1 1:153-7.

24. Gutiérrez AM, Montes A, Gutiérrez-Panizo C, Fuentes P, De La Cruz-Sánchez E. Gender influence on the salivary protein profile of finishing pigs. J Proteome. 2018;178:107-13.

25. Gutiérrez AM, Martínez-Subiela S, Soler L, Pallarés FJ, Cerón JJ. Use of saliva for haptoglobin and $\mathrm{C}$-reactive protein quantifications in porcine respiratory and reproductive syndrome affected pigs in field conditions. Vet Immunol Immunopathol. 2009;132:218-23.

26. Sánchez J, García A, Ruiz JM, Montes AM, Cabezas-Herrera J, Ros-Lara S, De la Cruz E, Gutiérrez AM. Porcine Breed, Sex, and Production Stage Influence the Levels of Health Status Biomarkers in Saliva Samples. Front Vet Sci. 2019. https://doi.org/10.3389/fvets.2019.00032.

27. Gutiérrez AM, Escribano D, Fuentes M, Cerón JJ. Circadian pattern of acute phase proteins in the saliva of growing pigs. Vet J. 2013;196:167-70.

28. Parra MD, Fuentes P, Tecles F, Martínez-Subiela S, Martínez JS, Muñoz A, Cerón JJ. Porcine acute phase protein concentrations in different diseases in field conditions. J Veterinary Med Ser B. 2006;53:488-93.

29. Heegaard PM, Stockmarr A, Piñeiro M, Carpintero R, Lampreave F, Campbell FM, Eckersall PD, Toussaint MJ, Gruys E, Sorensen NS. Optimal combinations of acute phase proteins for detecting infectious disease in pigs. Vet Res. 2011;17:42-50. 
30. Darczuk D, Krzysciak W, Vyhouskaya P, Kesek B, Galecka-Wanatowicz D, Lipska W, Kaczmarzyk T, Gluch-Lutwin M, Mordyl B, Chomyszyn-Gajewska M. Salivary oxidative status in patients with oral lichen planus. J Physiol Pharmacol. 2016:67:885-94.

31. Morán L, Andrés S, Bodas R, Prieto N, Giráldez FJ. Meat texture and antioxidant status are improved when carnosic acid is included in the diet of fattening lambs. Meat Sci. 2012;91:430-4.

32. Lykkesfeldt J, Svendsen O. Oxidants and antioxidants in disease: oxidative stress in farm animals. Vet J. 2007;173:502-11.

33. Monaghan P, Metcalfe NB, Torres R. Oxidative stress as a mediator of life history trade-offs: mechanisms, measurements and interpretation. Ecol Lett. 2009;12:75-92

34. Lauritzen B, Lykkesfeldt J, Skaanild MT, Angen Ø, Nielsen JP, Friis C. Putative biomarkers for evaluating antibiotic treatment: an experimental model for porcine Actinobacillus pleuropneumoniae infection. Res Vet Sci. 2003;74:261-70.

35. Rink L, Haase H. Zinc homeostasis and immunity. Trends Immunol. 2007;28:1-4.

36. Wellinghausen $\mathrm{N}$, Kirchner $\mathrm{H}$, Rink L. The immunobiology of zinc. Immunol Today. 1997;18:519-21.

37. Hood Ml, Skaar EP. Nutritional immunity: transition metals at the pathogenhost interface. Nat Rev Microbiol. 2012;10:525-37.

38. Rotruck JT, Pope AL, Ganther HE, Swanson AB, Hafeman DG, Hoekstra WG. Selenium: biochemical role as a component of glutathione peroxidase. Science. 1973;179:588-90.

39. Raszyk J, Toman M, Gajdůsková V, Nezveda K, Ulrich R, Jarosová A Docekalová H, Salava J, Palác J. Effects of environmental pollutants on the porcine and bovine immune systems. Vet Med. 1997;42:313-7.

40. Gutiérrez AM, Martínez-Subiela S, Cerón JJ. Evaluation of an immunoassay for determination of haptoglobin concentration in various biological specimens from swine. Am J Vet Res. 2009;70:691-6.

\section{Publisher's Note}

Springer Nature remains neutral with regard to jurisdictional claims in published maps and institutional affiliations.

Ready to submit your research? Choose BMC and benefit from:

- fast, convenient online submission

- thorough peer review by experienced researchers in your field

- rapid publication on acceptance

- support for research data, including large and complex data types

- gold Open Access which fosters wider collaboration and increased citations

- maximum visibility for your research: over $100 \mathrm{M}$ website views per year

At $\mathrm{BMC}$, research is always in progress.

Learn more biomedcentral.com/submissions 